\title{
Radiologic Changes of Operated and Adjacent Segments after Anterior Cervical Microforaminotomy
}

\author{
Jang Ho Ahn, Moon Sun Park, Seong Min Kim, Seung Young Chung, \\ Do Sung Lee, Ki Seok Park \\ Department of Neurosurgery, Eulji University School of Medicine, Daejeon, Korea
}

\begin{abstract}
Objective: Anterior cervical microforaminotomy (ACMF) is a motion-preserving surgical procedure. The purpose of this study is to assess radiologic changes of operated and adjacent segments after ACMF.

Methods: We retrospectively reviewed 52 patients who underwent ACMF between 1998 and 2008. From X-ray film-based changes, disc height and sagittal range of motion (ROM) of operated and adjacent segments were compared at preoperative and last followup periods. Radiological degeneration of both segments was analyzed as well.

Results: The mean follow-up period was 48.2 months. There were 78 operated, 52 upper adjacent, and 38 lower adjacent segments. There were statistically significant differences in the ROM and disc height of operated segment between preoperative and last follow-up periods. However, there were no statistically significant differences in the ROM and disc height of adjacent segment between both periods. Radiological degenerative changes of operated segments were observed in 30\%. That of adjacent segments was observed in 11 and $11 \%$ at upper and lower segments, respectively.

Conclusion: After mean 4-year follow-up periods, there were degenerative changes of operated segments. However, ACMF preserved motion and prevented degenerative changes of adjacent segments.
\end{abstract}

Key Words: Cervical radiculopathy $\cdot$ Anterior foraminotomy $\cdot$ Adjacent segment disease $\cdot$ Disc height $\cdot$ Range of motion

\section{INTRODUCTION}

Cervical radiculopathy caused by a compressive lesion arising from degenerative spondylotic change tends to be surgically treated either by discectomy with or without interbody fusion via an anterior or posterior surgical approach. The initial surgical management was a posterior laminectomy or a smaller keyhole foraminotomy approach that provided exposure of the nerve root that may include removal of a nonvisualized disc herniation or osteophytes ventral to the nerve. Many surgeons continue to use the posterior foraminal procedure today, but the difficulty of an indirect posterior exposure and inability to remove some ventral lesions led to the current and more common use of anterior discectomy procedures ${ }^{5)}$. Anterior cervical discectomy and fusion (ACDF) has been used safely over the past 50 years ${ }^{4}$. Since the technique of ACDF was first introduced by Cloward ${ }^{1)}$, Smith and Robinson ${ }^{17)}$, it

- Received: July 20, 2016 • Revised: September 22, 2016

- Accepted: September 24, 2016

Corresponding Author: Ki Seok Park

Department of Neurosurgery, Eulji University Hospital, Eulji University School of Medicine, 95 Dunsanseo-ro, Seo-gu, Daejeon 35233, Korea Tel: +82-42-611-3275, Fax: +82-42-611-3826

E-mail: ks3432@eulji.ac.kr

@ This is an open access article distributed under the terms of the Creative Commons Attribution Non-Commercial License (http://creativecommons.org/licenses/by-nc/4.0/) which permits unrestricted non-commercial use, distribution, and reproduction in any medium, provided the original work is properly cited. has become a standard of care for cervical spondylotic myelopathy and radiculopathy caused by disc prolapses and degenera tive osteophytes. Although anterior cervical fusion is an established technique, it eliminates motion segments and this may lead to increase in mechanical stress at adjacent disc levels, thereby accelerating degenerative changes and producing clinical symptoms with time: the so-called 'adjacent segment disease.' Anterior cervical microforaminotomy (ACMF) is a new microsurgical technique developed to accomplish direct nerve root decompression via the anterior approach while preserving the functioning motion segments and avoiding the need for fusion that was refined by Jho" in 1966. To our knowledge, there is rare report assessing the incidence of adjacent segment degeneration after ACMF. Therfore, the purpose of this study was to assess the radiologic changes of the operated and adjacent segments after ACMF.

\section{MATERIALS AND METHODS}

\section{Patient Selection}

Between May 1998 and November 2008, 87 patients were treated for unilateral radiculopathy with ACMF. Exclusion criteria for the current study were the cervical radiculopathy with abnormal bony involvement, ossification of posterior longitudinal ligament (PLL), kyphotic deformity, previous cervical surgery, bilateral lesion, and cervical myelopathy. All pati- 
ents were observed clinically and radiologically over a year and had a history of radiculopathic symptoms refractory to conservative treatments for a minimum of 6 weeks or motor weakness.

\section{Surgical Procedure}

We performed a transuncal approach introduced by Jho". The detailed description of surgical method was shown in our previous reports ${ }^{11,13)}$. The brief description was followed: a conventional ACDF approach was made with optimal location on the side of the lesion. After the ipsilateral longus colli muscle (LCM) was approach by the same method of conventional ACDF, a cervical retractor was inserted. The medial part of LCM was resected or divided to expose the medial parts of the transverse processes of the upper and lower vertebrae. Using high-speed drill, the uncovertebral joint was removed preserving intervertebral disc and medial part of the uncovertebral joint as possible. When PLL was encountered, the thin cortical bone of the uncinate process covering the vertebral artery was fractured and removed. The herniated disc material or osteophyte compressing the root was removed with microforcep or 1-mm punch. After making sure of detecting the pulsation by cerebrospinal fluid of nerve root, the decompression was completed.

\section{Clinical and Radiographic Evaluation}

Clinical evaluation included the visual analogue scale (VAS), and neck disability index (NDI) ${ }^{19)}$. Patients were asked to check the NDI and grade their pain intensity before surgery and last follow-up period. The NDI scores varied from 0 to 50. Pain intensity was reported from 0 to 10 using a subjective VAS ( 0 , no pain; 10 , the worst pain). Radiographic evaluation included static and dynamic flexion-extension radiographs in an upright position at preoperative and last follow-up period. The segmental range of motion (ROM) for operated and adjacent segment except C7-T1 was measured using the Cobb method with the Patient Archiving Communication System software (M-view, Marosis, Seoul, Korea). The ROM was calculated by the difference in Cobb angles between full flexion and extension in lateral cervical radiographs. Lordosis was expressed as a negative value and kyphosis was expressed as a positive value. Disc height was measured along a straight line passing through the central points of the adjacent vertebral bodies. We also compared the preoperative disc height with last follow-up disc height at the operated and adjacent segments except C7-T1 using static neutral lateral radiographs. According to prepublished criteria for degeneration, the radiologic evidence of degeneration for operated and adjacent segments in the plain radiographs included new anterior osteophyte formation or enlargement of existing osteophytes, increased narrowing of a disc space ( $\geq 30 \%)$, and new or increased calcification of anterior longitudinal ligament (ALL) documented on serial plain radiographs ${ }^{12,15)}$. To evaluate the diffe- rence in the clinical and radiological results of each period, we used the paired t-test with IBM SPSS ver. 18.0 (IBM Co., Armonk, NY, USA). A $\mathrm{p}<0.05$ was considered significant.

\section{RESULTS}

\section{Demographics}

The patients' characteristics are shown in Table 1. The clinical and radiographic follow-up was possible in 52 patients. We examined the surgical results for 52 patients who had undergone ACMF. The follow-up period was 37-111 months (mean, 48.2 months). In theses 52 patients, there were 24 men and 28 women. The age of the patients at the time of surgery ranged from 31 to 71 years (mean, 50 years). Of the 52 patients, Single-level operations were performed in 37 patients (71.1\%), 2-level operations in 14 patients (26.9\%), and 3-levels in 1 patient (2\%). Target levels included were $\mathrm{C} 5-\mathrm{C} 6(\mathrm{n}=38), \mathrm{C} 6-\mathrm{C} 7$ $(\mathrm{n}=18), \mathrm{C} 4-\mathrm{C} 5(\mathrm{n}=10)$, and $\mathrm{C} 3-\mathrm{C} 4(\mathrm{n}=2)$.

\section{Clinical Results}

The clinical results are shown in Table 2. The mean preoperative VAS and NDI scores were 7.5 and 24.9, respectively.

Table 1. Patients' characteristics $(\mathrm{n}=52)$

\begin{tabular}{ll}
\hline \multicolumn{1}{c}{ Characteristic } & \multicolumn{1}{c}{ Value } \\
\hline Age (yr), mean (range) & $50(31-71)$ \\
Sex, male:female & $24: 28$ \\
Location, right/left & $28: 26$ \\
Operated level & \\
1 Level & 37 \\
2 Levels & 14 \\
3 Levels & 1 \\
C3-4 & 2 \\
C4-5 & 20 \\
C5-6 & 38 \\
C6-7 & 18 \\
\hline
\end{tabular}

Table 2. Clinical and radiological assessment of operated and adjacent segments

\begin{tabular}{lrrr}
\hline \hline \multicolumn{1}{c}{ Variable } & \multicolumn{3}{c}{ Preoperative } \\
\hline Vast follow-up & p-value \\
\hline Visual analogue scale & $7.5 \pm 2.2$ & $2.1 \pm 1.0$ & $<0.001$ \\
Neck disability index & $24.9 \pm 8.3$ & $15.6 \pm 6.8$ & $<0.001$ \\
Disc height (mm) & & & \\
$\quad$ Operated segment $(\mathrm{n}=78)$ & $5.8 \pm 4.0$ & $4.6 \pm 1.1$ & $<0.001$ \\
$\quad$ Upper segment $(\mathrm{n}=52)$ & $6.2 \pm 1.2$ & $5.8 \pm 1.5$ & 0.168 \\
$\quad$ Lower segment $(\mathrm{n}=38)$ & $6.2 \pm 1.6$ & $5.9 \pm 1.9$ & 0.136 \\
Range of motion (degree) & & & \\
$\quad$ Operated segment & $7.7 \pm 4.3$ & $5.9 \pm 3.6$ & 0.019 \\
$\quad$ Upper segment & $10.1 \pm 4.3$ & $9.3 \pm 3.2$ & 0.517 \\
Lower segment & $6.1 \pm 3.6$ & $6.3 \pm 4.2$ & 0.655 \\
\hline
\end{tabular}

Values are presented as mean \pm standard deviation. 
The mean last follow-up scores were improved to 2.1 and 15.6, respectively. The clinical outcome scores were statistically improved $(\mathrm{p}<0.05)$. There was no same level recurrence or radiculopathy of the other levels after ACMF. There were no surgery related complications.

\section{Radiological Results}

\section{1) ROM of the operated and adjacent segments}

The ROM of operated and adjacent segments is shown in Table 2. The mean ROM of operated segment was $7.7^{\circ} \pm 4.3^{\circ}$ on admission and $5.9^{\circ} \pm 3.6^{\circ}$ on last follow-up period. There was statistically significant difference in the ROM of operated segment between preoperative and last follow-up periods $(\mathrm{p}=0.019)$. The mean ROM of upper adjacent segment was $10.1^{\circ} \pm 4.3^{\circ}$ on admission and $9.3^{\circ} \pm 3.2^{\circ}$ on last follow-up period. The mean ROM of lower adjacent segment were $6.1^{\circ} \pm$ $3.6^{\circ}$ on admission and $6.3^{\circ} \pm 4.2^{\circ}$ on last follow-up period. There were no statistical differences in the ROM of upper and lower adjacent segment between preoperative and last follow-up period.

\section{2) Intervertebral disc height}

The disc heights of operated and adjacent segments are shown in Table 3. The disc height of operated segment was $5.8 \pm 4.0 \mathrm{~mm}$ on admission and $4.6 \pm 1.1 \mathrm{~mm}$ on last follow-up period. The disc height of operated segment was significantly decreased on last follow-up period $(\mathrm{p}<0.001)$. The disc height of upper adjacent segment was $6.2 \pm 1.2 \mathrm{~mm}$ on admission and $5.8 \pm 1.5 \mathrm{~mm}$ on last follow-up period. The disc height of lower adjacent segment was $6.2 \pm 1.58$ on admission and $5.9 \pm 1.9$ $\mathrm{mm}$ on last follow-up period. There were no statistical differences in the disc height of upper and lower adjacent segment between on admission and last follow-up period.

\section{3) Radiological degenerative changes}

The radiological degenerative changes are shown in Table 3. Among the 78 operated segments, new anterior osteophyte formation was observed in 14, calcification of ALL in 4, and disc space narrowing more than $30 \%$ was observed in 9 . Because 3 segments have both osteophyte formation and disc space narrowing, radiologic change was observed in 24 segments (30\%) (Fig. 1). We had 52 upper adjacent segments and
38 lower adjacent segments, considering multilevel and C6-7 ACMF. Among 52 upper adjacent segments, new anterior osteophyte formation was observed in 6 (11\%) (Fig. 2). There was no disc space narrowing and calcification of ALL. Among 38 lower adjacent segments, the radiologic change was observed in 4 (11\%). There were three cases of new anterior osteophyte formation and one case of calcification of ALL. But, there was no symptomatic case that requires surgery due to degeneration of operated and adjacent segments.

\section{DISCUSSION}

For over 50 years, ACDF has been the treatment of choice for symptomatic cervical radiculopathy ${ }^{4}$. Although it has been

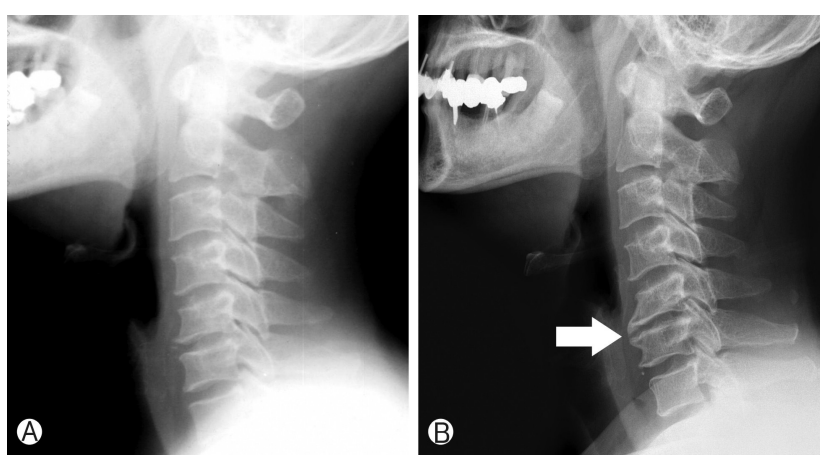

Fig. 1. Lateral cervical radiographs preoperative (A) and 111 months (B) after C5-6 anterior cervical microforaminotomy in 52-year-old male. The new anterior osteophyte and disc space narrowing were shown (arrow).

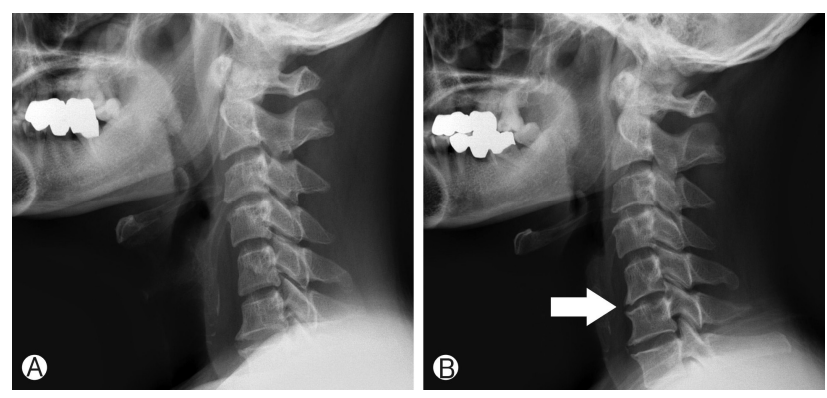

Fig. 2. Lateral cervical radiographs preoperative (A) and 46 months (B) after C6-7 anterior cervical microforaminotomy in 63-year-old male. The new anterior osteophyte of upper adjacent segment (C5-6) was shown (arrow).

Table 3. Radiological degenerative changes of operated and adjacent segments

\begin{tabular}{lccc}
\hline \hline Variable & Operated segment (30\%) & Upper segment (11\%) & Lower segment (11\%) \\
\hline New or enlarged anterior osteophyte formation & 14 & 6 & 3 \\
Calcification of ALL & 4 & 0 & 1 \\
Increased narrowing of disc space $(\geq 30 \%)$ & 9 & 0 & o \\
\hline
\end{tabular}

ALL, anterior longitudinal ligament. 
proven to clinically provide good result, it may cause pseudoarthrosis, implant failure and more recently, adjacent level disease $^{4,16)}$. Previous studies have revealed that a fused segment increases biomechanical stress and motion at adjacent lev$\mathrm{els}^{4,15)}$. Increased stress may accelerate degenerative changes and development of symptoms. So, adjacent segment disease is a long-term complication of ACDF, which may require another surgical procedure ${ }^{2,3)}$. Hilibrand et al. ${ }^{7}$ reported that surgery was necessary in $2.9 \%$ of patients per year due to symptomatic adjacent segment disease whereas the other study revealed that new symptomatic adjacent disc disease occurred at a rate of $13.9 \%$ (6.9\%, annually) after fusion surgery ${ }^{15}$. To avoid this complication of ACDF, particularly in young patients, the functioning motion should be preserved during surgery whenever possible. So, ACMF was introduced with the advantage of maintaining the integrity of the intervertebral disc and spinal stability ${ }^{9,18}$. In our study, the ROM of adjacent segments was well preserved at the last follow-up radiographs. But, contrast to our thought that after ACMF, the ROM of operated segment would be preserved, the ROM of operated segment was significantly decreased at the last follow-up radiographs. The disc height of adjacent segments after ACMF was well preserved. However, that of operated segments after ACMF was decreased significantly. The decrease of disc height in operated segment after ACMF was reported in our previous studies $^{10,11)}$. In our series, $30 \%$ of the operated segments showed radiological degenerative changes in the last follow-up radiographs such as osteophyte formation, calcification of ALL, and, increased narrowing of a disc space ( $\geq 30 \%)$. We think that operated segment might be more degenerated to fuse eventually because of the previous advanced spondylosis and the progressive bony regrowth in the foraminotomy site. Park et al. ${ }^{14)}$ reported similar results for the ROM and the disc height of operated segment after ACMF in long-term study. They reported that 40 of 43 operated segments (93\%) were defined as degenerated in their study, which was larger than our study (30\%). It may be due to their criteria about the degeneration of disc space which was only increased or new narrowing of disc space by more than $10 \%$. They suggested that partial destruction of disc space by ACMF seems to be responsible for same-level degeneration.

In adjacent segment disease, Hilibrand et al. ${ }^{7}$ used the term "adjacent segment degeneration to describe radiologic change at levels adjacent to a previous spinal fusion without any clinical findings and the term "adjacent segment disease to refer to the development of new clinical symptoms that correspond to radiologic changes adjacent to the level of a previous spinal fusion." There were few reports about it after ACMF. Park et al. ${ }^{14)}$ reported that radiological adjacent segment degeneration after ACMF was noted in 6 and $11 \%$ at the upper and lower segments. There were 2 patients (4.5\%) required additional surgery for adjacent segment disease. In adjacent segment disease after ACDF, some authors suggested that the radiological and clinical incidence of cervical spondylosis incre ases with age and, therefore it may be that adjacent segment disease occurs as a consequence of the natural history of spondylotic disease, rather than due to the cervical fusion itself ${ }^{8}$. Herkowitz et al. ${ }^{6}$ reported on 44 patients with cervical radiculopathy after ACDF or posterior foraminotomy without fusion. After fusion, 39\% of patients developed radiological adjacent segment degeneration. However, $50 \%$ of patients undergoing posterior foraminotomy also developed radiological changes of disc degeneration at the operated and adjacent levels, implying that fusion is not the only factor that influences the risk of radiological adjacent segment disease. In another similar study, Henderson et al. ${ }^{5}$ found that $9 \%$ of 846 patients with posterior foraminotomy and discectomy developed adjacent segment disease over an average follow-up period of 3 years. In a review of literatures, there is one report comparing with cervical arthroplasty. Yi et al. $^{20)}$ reported that there was no statistical difference in the ROM of adjacent segments between ACMF and arthroplasty. But, it was only one year follow-up. The current study showed that radiological adjacent segment degeneration after ACMF was noted in 11 and $11 \%$ at the upper and lower segments. They were asymptomatic. In small series of this study, it was difficult to clarify whether the real adjacent segment degeneration was caused by this surgery or was just spondylotic change due to aging. We expect that $\mathrm{ACMF}$ as a motion preserving method might be better than ACDF in preventing adjacent segment degeneration, although we did not compare with ACDF.

Although this study highlights the efficacy of radiological changes after ACMF, this study has important limitations, primarily associated with the small sample size and lack of control group. In addition, this study dealt with X-ray film-based changes of segments. Future studies will be required to ascertain the potential harm of spondylotic change in the operated segments and compare ACMF with other procedures like as fusion surgery and cervical arthroplasty.

\section{CONCLUSION}

ACMF preserves motion and may prevent degenerative changes of adjacent segments. Although ACMF shows spondylotic changes in operated segments, it provides favorable outcomes. Further investigation will be needed.

\section{CONFLICT OF INTEREST}

No potential conflict of interest relevant to this article was reported.

\section{REFERENCES}

1. Cloward RB: The anterior approach for removal of ruptured cervical disks. 1958. J Neurosurg Spine 6:496-511, 2007

2. Eck JC, Humphreys SC, Lim TH, Jeong ST, Kim JG, Hodges SD, et al: Biomechanical study on the effect of cervical spine fusion on adjacent-level intradiscal pressure and segmental motion. Spine (Phila Pa 1976) 27:2431-2434, 2002 
3. Fuller DA, Kirkpatrick JS, Emery SE, Wilber RG, Davy DT: A kinematic study of the cervical spine before and after segmental arthrodesis. Spine (Phila Pa 1976) 23:1649-1656, 1998

4. Goffin J, Geusens E, Vantomme N, Quintens E, Waerzeggers Y, Depreitere B, et al: Long-term follow-up after interbody fusion of the cervical spine. J Spinal Disord Tech 17:79-85, 2004

5. Henderson CM, Hennessy RG, Shuey HM Jr, Shackelford EG: Posterior-lateral foraminotomy as an exclusive operative technique for cervical radiculopathy: a review of 846 consecutively operated cases. Neurosurgery 13:504-512, 1983

6. Herkowitz HN, Kurz LT, Overholt DP: Surgical management of cervical soft disc herniation. A comparison between the anterior and posterior approach. Spine (Phila Pa 1976) 15:10261030, 1990

7. Hilibrand AS, Carlson GD, Palumbo MA, Jones PK, Bohlman $\mathrm{HH}$ : Radiculopathy and myelopathy at segments adjacent to the site of a previous anterior cervical arthrodesis. J Bone Joint Surg Am 81:519-528, 1999

8. Humphreys SC, Hodges SD, Patwardhan A, Eck JC, Covington LA, Sartori M: The natural history of the cervical foramen in symptomatic and asymptomatic individuals aged 20-60 years as measured by magnetic resonance imaging. A descriptive approach. Spine (Phila Pa 1976) 23:2180-2184, 1998

9. Jho HD: Microsurgical anterior cervical foraminotomy for radiculopathy: a new approach to cervical disc herniation. J Neurosurg 84:155-160, 1996

10. Jung SS, Chung JC, Park KS, Chung SY, Park MS, Ha HG: Longterm follow-up results of anterior cervical microforaminotomy. Korean J Spine 7:66-72, 2010

11. Kim YG, Lee JS, Park MS, Ha HG: Midterm follow-up results of anterior cervical microforaminotomy. J Korean Neurosurg Soc 35:250-255, 2004
12. Maldonado CV, Paz RD, Martin CB: Adjacent-level degeneration after cervical disc arthroplasty versus fusion. Eur Spine J 20 Suppl 3:403-407, 2011

13. Park SJ, Ha HG, Jung H, Lee SK, Park MS: Anterior cervical microforaminotomy: a minimally invasive anterolateral approach for spondylotic lesions. J Korean Neurosurg Soc 29:87-94, 2000

14. Park YK, Moon HJ, Kwon TH, Kim JH: Long-term outcomes following anterior foraminotomy for one- or two-level cervical radiculopathy. Eur Spine J 22:1489-1496, 2013

15. Robertson JT, Papadopoulos SM, Traynelis VC: Assessment of adjacent-segment disease in patients treated with cervical fusion or arthroplasty: a prospective 2-year study. J Neurosurg Spine 3:417-423, 2005

16. Silber JS, Anderson DG, Daffner SD, Brislin BT, Leland JM, Hilibrand AS, et al: Donor site morbidity after anterior iliac crest bone harvest for single-level anterior cervical discectomy and fusion. Spine (Phila Pa 1976) 28:134-139, 2003

17. Smith GW, Robinson RA: The treatment of certain cervical-spine disorders by anterior removal of the intervertebral disc and interbody fusion. J Bone Joint Surg Am 40-A:607-624, 1958

18. Snyder GM, Bernhardt M: Anterior cervical fractional interspace decompression for treatment of cervical radiculopathy: a review of the first 66 cases. Clin Orthop Relat Res (246):92-99, 1989

19. Vernon H, Mior S: The Neck Disability Index: a study of reliability and validity. J Manipulative Physiol Ther 14:409-415, 1991

20. Yi S, Lim JH, Choi KS, Sheen YC, Park HK, Jang IT, et al: Comparison of anterior cervical foraminotomy vs arthroplasty for unilateral cervical radiculopathy. Surg Neurol 71:677-680, 2009 